\title{
Hormonal contraception increases risk of asthma among obese but decreases it among nonobese subjects: a prospective, population-based cohort study
}

\author{
Melanie C. Matheson ${ }^{1}$, John A. Burgess ${ }^{1}$, Melisa Y.Z. Lau ${ }^{1}$, Adrian J. Lowe ${ }^{1}$, \\ Lyle C. Gurrin ${ }^{1}$, John L. Hopper ${ }^{1}$, Graham G. Giles ${ }^{2}$, David P. Johns ${ }^{3}$, \\ E. Haydn Walters ${ }^{3}$, Michael J. Abramson ${ }^{4}$, Francisco Gómez Real ${ }^{5,6}$ and \\ Shyamali C. Dharmage ${ }^{1}$
}

Affiliations: ${ }^{1}$ Centre for Epidemiology and Biostatistics, The University of Melbourne, Melbourne, Australia ${ }^{2}$ Cancer Epidemiology Centre, Cancer Council Victoria, Melbourne, Australia. ${ }^{3}$ Menzies Research Institute, University of Tasmania, Hobart, Australia. ${ }^{4}$ Department of Epidemiology and Preventive Medicine, Monash University, Melbourne, Australia. ${ }^{5}$ The Department of Gynecology and Obstetrics, Haukeland University Hospital, Bergen, Norway. ${ }^{6}$ The Bergen Respiratory Research Group, Institute of Medicine, University of Bergen, Bergen, Norway.

Correspondence: Melanie C. Matheson, Centre for Epidemiology and Biostatistics, Melbourne School of Population and Global Health, Allergy and Lung Health Unit, The University of Melbourne, Level 3, 207 Bouverie Street, Carlton, Victoria 3053, Australia. E-mail: mcmatdunimelb.edu.au

ABSTRACT Epidemiological data on asthma suggest a sex difference that varies with age. Hormonal effects have been suggested as a possible explanation for these differences but there is a scarcity of evidence on these relationships. Our objective was to examine the relationship between reproductive factors and asthma risk among females and to examine whether body mass index (BMI) modifies this relationship.

Female participants in the 2004 fifth decade follow-up postal survey of the Tasmanian Longitudinal Health Study formed the study population. Reproductive history and data on hormonal contraceptive (HC) use were collected on 2764 females. Multiple logistic regression was used to assess the association between the reproductive factors and current asthma.

The mean age of participants was 43 years and the prevalence of middle-aged current asthma was $12.8 \%$. Females with very early menarche ( $\leqslant 10$ years) had higher odds of middle-aged current asthma (OR 1.91, 95\% CI 1.14-3.2). Pregnancy history (number of births and age at first pregnancy) were not associated with current asthma risk at 44 years. Ever having used HCs, years of use and age started using HCs were not individually associated with current asthma risk. However, body mass index significantly modified the relationship between $\mathrm{HC}$ use and asthma. We found increasing years of pill use was associated with a significantly increased risk of current asthma in overweight/obese women but a reduced risk in normal weight women (interaction $\mathrm{p}=0.015$ ).

Hormonal effects from use of HCs and early menarche may contribute to the sex differential in asthma risk. Our findings suggest that in obese women with a history of long-term HC use may be at an increased risk of chronic respiratory disease, and regular monitoring for asthma and asthma symptoms may be recommended.

$@$ ERSpublications

Overweight or obese women are at increased risk of asthma if they use hormonal contraceptives for extended periods http://ow.ly/SwY8p

This article has supplementary material available from openres.ersjournals.com

Received: May 142015 | Accepted after revision: Sept 142015

Support statement: This study was funded by The National Health and Medical Research Council (NHMRC) of Australia, LEW Carty Charitable Fund, Clifford Craig Medical Research Trust of Tasmania, The Asthma Foundation of Victoria and Asthma Foundation of Tasmania. M.C. Matheson, S.C. Dharmage, A.J. Lowe, J.A. Burgess and E.H. Walters were supported by the NHMRC. M.Y.Z. Lau was supported by a Marjory Edwards OAM PhD Scholarship from Asthma Australia.

Conflict of interest: Disclosures can be found alongside this article at openres.ersjournals.com

Copyright (CERS 2015. This article is open access and distributed under the terms of the Creative Commons Attribution Non-Commercial Licence 4.0 . 


\section{Introduction}

Asthma prevalence and incidence vary by sex over the life span. Childhood asthma is more common in boys but around puberty, the prevalence/incidence switches to be higher in girls $[1,2]$. This continues into adult life, with women having higher asthma prevalence than men [3]. Women also report worse symptoms and a greater effect on quality of life [4]. The reasons for these sex reversals are not well understood. Animal and human studies suggest that female sex hormones may play an important role. It is thought that these hormones can affect lung inflammation, airway smooth muscle and the function of the immune system [5, 6]. In addition, an interaction between these hormones and obesity has been reported [7-9].

Marked changes in female sex hormones result from menarche, pregnancy, use of hormonal contraceptives (HCs), use of hormone replacement therapy and the menopause. Many of these factors have been linked to asthma risk $[8,10-12]$, but have tended to be investigated in isolation without taking into account the possible confounding effects of each other. Furthermore, while there is evidence that the association between obesity and asthma is seen mainly among females, most studies have not taken into account the possibility of interaction between hormonal effects and obesity. Obesity has been identified as part of an asthma phenotype characterised by later disease onset and a higher proportion of females [13]. Both cross-sectional and longitudinal studies have reported a higher incidence of asthma or wheeze in overweight and obese females compared to normal weight females $[9,14,15]$.

Very few studies have examined the joint effects of reproductive factors and obesity on asthma outcomes, despite the observed links between them. Hence, the aim of this study was to investigate several reproductive factors (specifically age at menarche, HC use and number of pregnancies), and identify any interaction between these factors and body mass index (BMI) on asthma risk. We used data on women from the Tasmanian Longitudinal Health Study (TAHS) who were perimenopausal at the time of survey.

\section{Methods}

\section{Tasmanian Longitudinal Health Study}

The methods of the baseline study and subsequent follow-up have been published elsewhere [16, 17]. In brief, TAHS began in 1968 when 8583 Tasmanian children (probands) born in 1961 and attending school in Tasmania were enrolled. Parents completed a respiratory health questionnaire for their child, who then underwent a clinical examination and lung function measurements. Follow-up surveys were completed in 1974, 1979 and 1992 at the ages of 13, 18 and 31 years, respectively. The most recent follow-up study started in 2002 when probands were in their fifth decade of life. Overall response rates for tracing and the postal survey have been reported previously [18]. This analysis was restricted to the female respondents, for whom we traced $3510(83.8 \%)$ of the original 1968 cohort to an address and achieved a response to a postal survey from 2776 (80.7\%). The 2004 follow-up study was approved by the Human Research Ethics Committee of the University of Melbourne, Melbourne, Australia (HREC number 010626X). All participants provided written informed consent.

\section{Outcome definitions}

"Current asthma" was defined in the fifth decade follow-up by an affirmative response to the question "Have you, at any time in your life, suffered from attacks of asthma or wheezy breathing?" and having the last attack of asthma within the previous year. "Ever asthma after menarche" was defined as reporting having asthma in the fifth decade follow-up survey and reporting for the question "At what age did these attacks begin?" an age later than that reported for the onset of menarche.

\section{Exposure definitions}

Information on reproductive characteristics was collected in the fifth decade follow-up postal survey. Age at menarche was defined by the question "What was your age when you had your first period?". This was then divided into the categories: $\leqslant 10$ years, 11 years, $12-13$ years, $14-15$ years and $>15$ years.

HC use was defined by the questions "Have you ever used birth control pills or other hormonal contraceptives (implants or injections)?" and "Are you currently taking birth control pills or other hormonal contraceptives?". HC use was then categorised into never, past or current use. Age starting HC was obtained from the question "At what age did you first use birth control pills or other hormonal contraceptives?”. Age when starting HC was then divided into categories: never, $\leqslant 16$ years, $17-18$ years and $\geqslant 19$ years. Years of $\mathrm{HC}$ use was obtained from the question "Over your whole lifetime, in total how many months or years have you taken birth control pills or other hormonal contraceptives?". Years of HC use was then divided into seven categories: nil use, 0.1-5 years, 5.1-10 years, 10.1-15 years, 15.1-20 years, $20.1-25$ years and $\geqslant 25$ years.

The women were also asked about current and past pregnancies. If they reported pregnancy, they were asked more details including their age when they became pregnant. Total number of live births was 
categorised as no, one, two, three and four or more live births. Age at birth of first child was grouped into the following categories: no children, $\leqslant 20$ years, $21-24$ years, $25-28$ years and $\geqslant 29$ years.

Adult BMI was calculated from self-reported height and weight at the fifth decade follow-up postal survey, and categorised as normal weight $\left(\leqslant 25 \mathrm{~kg} \cdot \mathrm{m}^{-2}\right)$ or overweight/obese $\left(>25 \mathrm{~kg} \cdot \mathrm{m}^{-2}\right)$ according to the definitions suggested by the World Health Organisation [19]. Childhood BMI was calculated from measured height and weight at the baseline survey when participants were aged 7 years. Childhood BMI was also categorised into normal weight or overweight/obese according to the definitions suggested by CoLE et al. [20].

\section{Confounders}

"Current asthma at age 7" was defined by an affirmative response by the parents to the question "Has he/ she at any time of his/her life suffered from attacks of asthma or of wheezy breathing?" and having had the last attack $<12$ months ago in 1968. Maternal and paternal history of allergy was defined as a parent who reported a history of either asthma or allergic rhinitis in the 1968 survey. Smoking status of the participants was classified as current, past and never-smokers. Adult socioeconomic status (SES) was defined by the participant's occupation as reported in the fifth decade follow-up and grouped into five categories based on skill level: 1) manager/administrators, 2) associate professionals, 3) tradespersons, 4) production/sales/clerical workers and 5) labourers/house persons.

\section{Statistical analysis}

The association between reproductive factors and middle-aged current asthma was examined while adjusting for confounding using multivariable logistic regression. Age at menarche was additionally examined in relation to any asthma after the onset of menarche. The interaction between reproductive factors and BMI in childhood and adulthood was examined for the middle-aged current asthma and stratified results are presented when the $\mathrm{p}$-value for the interaction term was at least modest $(\mathrm{p} \leqslant 0.1)$.

All models were adjusted for maternal atopy, current smoking status and SES. Other potential confounders mentioned above were assessed and retained in the model if inclusion changed the point estimate by $\geqslant 10 \%$. All analyses were performed using Stata Release 11.1 (Stata statistical software, release 11.1; StataCorp, College Station, TX, USA). A two-sided p-value of $<0.05$ was considered to be statistically significant.

\section{Results}

The mean \pm SD age of participants was $43 \pm 0.83$ years and the mean \pm SD adult BMI was $25.7 \pm 5.53 \mathrm{~kg} \cdot \mathrm{m}^{-2}$. Nearly $60 \%$ were past or current smokers with a median history of smoking of 12.8 pack-years (interquartile range 3.82-24.2 pack-years) (table 1). The prevalence of middle-aged current asthma was 12.8\% (95\% CI 11.6-14.1\%) and the prevalence of ever asthma after menarche was $21.5 \%$ (95\% CI 19.8-23.3\%).

The mean \pm SD age at menarche was $13.0 \pm 1.52$ years. The prevalence of very early menarche ( $\leqslant 10$ years) was $3.9 \%$ (95\% CI 3.2-4.7\%) while 5.4\% (95\% CI 4.6-6.3\%) had late menarche (>15 years old). There was a significantly increased risk of middle-aged current asthma in females who had very early menarche (OR 1.91, 95\% CI 1.14-3.20) (table 2). Childhood obesity did not confound the association between very early menarche and middle-aged current asthma (OR 2.05, 95\% CI 1.20-3.48). There was also a trend for an association between ever asthma after menarche and very early age at menarche ( $\leqslant 10$ years) (OR 1.54 , 95\% CI 0.93-2.55; $\mathrm{p}=0.10$ ) but this was further attenuated after additional adjustment for childhood BMI (OR 1.40, 95\% CI 0.82-2.40; $\mathrm{p}=0.22$ ). The number of live births and the age at birth of the first child were not associated with middle-aged current asthma (table 2). None of these associations, including age at menarche, were modified by childhood obesity or adult obesity.

The associations between HC use and current asthma in middle-age are presented in table 3 . There was no association between ever using HCs or the age at which a woman started using HC and current asthma (table 3). For years of using HCs, there was no association with asthma when grouped into categories or if assessed as a continuous measure (OR 0.99, 95\% CI 0.97-1.01; $\mathrm{p}=0.23$ ).

Next we examined if the relationships between reproductive factors and current middle-aged asthma were modified by BMI. For HC use, we found a statistically significant effect modification by BMI on the relationship between duration of $\mathrm{HC}$ use as a continuous variable and current asthma (interaction $\mathrm{p}=0.015$ ). Figure 1 displays the predicted probabilities of current asthma that were computed using the estimates from the multivariate regression model. In this model, in overweight/obese women with increasing years of pill use, there was a significantly increased risk of current asthma in middle-age (table 4). However, for normal-weight women, the effect was reversed, with increasing years of HC use being protective against current asthma in middle age (online supplementary table S1). We did not observe any effect modification by BMI at 7 years $(\mathrm{p}=0.76)$ on the relationship between duration of $\mathrm{HC}$ use and current asthma. 
TABLE 1 General and reproductive characteristics of the Tasmanian Longitudinal Health Study female participants

\begin{tabular}{|c|c|}
\hline Age $^{\#}$ years & $43.0 \pm 0.83$ \\
\hline Adult BMI $\mathrm{kg} \cdot \mathrm{m}^{-2}$ & $25.7 \pm 5.53$ \\
\hline Duration of pill use ${ }^{+}$years & $12.0 \pm 7.69$ \\
\hline Age at first menstruation ${ }^{\S}$ years & $12.9 \pm 1.52$ \\
\hline Age at first pregnancy $f$ years & $25.1 \pm 5.3$ \\
\hline \multicolumn{2}{|l|}{ Adult BMI categories } \\
\hline Normal & 1445 (53.9) \\
\hline Overweight/obese & $1235(46.1)$ \\
\hline \multicolumn{2}{|l|}{ Education } \\
\hline Grade 1-6 & $172(6.2)$ \\
\hline Grade 10 or 11 & $1356(49.1)$ \\
\hline Trade/apprenticeship & $693(25.1)$ \\
\hline University degree & $537(19.4)$ \\
\hline Missing & $6(0.2)$ \\
\hline \multicolumn{2}{|l|}{ SES } \\
\hline Manager/administrator & $733(26.5)$ \\
\hline Associate professional & $199(7.2)$ \\
\hline Tradespersons & 372 (13.5) \\
\hline Production/sales/clerical & $583(21.1)$ \\
\hline Labourer/house person & 849 (30.7) \\
\hline Missing & $28(1.0)$ \\
\hline \multicolumn{2}{|l|}{ Smoking } \\
\hline Never & $1110(40.2)$ \\
\hline Past & 829 (30.0) \\
\hline Current & 815 (29.5) \\
\hline Missing & $10(0.4)$ \\
\hline
\end{tabular}

Data are presented as mean \pm SD or $n(\%)$. BMI: body mass index; SES: socioeconomic status. ${ }^{\#}: \mathrm{n}=2763$; ๆ: $n=2679 ;^{+}: n=2753 ;{ }^{\S}: n=2718 ;{ }^{f}: n=2375$.

\section{Discussion}

In this perimenopausal group of women from a large population-based study, we found a statistically significant increased risk of current asthma at age 44 years and a trend towards statistical significance for

TABLE 2 Associations between age at menarche and pregnancy history, and current asthma at age 43 years

\begin{tabular}{|c|c|c|c|}
\hline \multirow[t]{2}{*}{ Variable } & \multicolumn{2}{|c|}{ Middle-aged current asthma } & \multirow[t]{2}{*}{ p-value } \\
\hline & $\%(n / N)$ & OR $(95 \% \mathrm{CI})$ & \\
\hline \multicolumn{4}{|c|}{ Age at menarche } \\
\hline$\leqslant 10$ years & $20.6(22 / 107)$ & $1.91(1.14-3.20)$ & 0.01 \\
\hline 11 years & $13.0(41 / 316)$ & $1.10(0.75-1.61)$ & 0.63 \\
\hline $12-13$ years & $12.1(164 / 1361)$ & 1.0 & \\
\hline $14-15$ years & $12.1(95 / 785)$ & $1.01(0.76-1.34)$ & 0.96 \\
\hline$>15$ years & $15.7(23 / 147)$ & $1.36(0.83-2.22)$ & 0.22 \\
\hline \multicolumn{4}{|l|}{ Live births $\mathrm{n}$} \\
\hline 0 & $12.6(48 / 382)$ & $0.82(0.56-1.20)$ & 0.31 \\
\hline 1 & $12.4(41 / 332)$ & $0.86(0.58-1.26)$ & 0.44 \\
\hline 2 & $12.8(144 / 1128)$ & 1.0 & \\
\hline 3 & $13.1(82 / 626)$ & $0.91(0.67-1.24)$ & 0.54 \\
\hline$\geqslant 4$ & 13.3 (39/293) & $0.99(0.67-1.47)$ & 0.98 \\
\hline \multicolumn{4}{|c|}{ Age at birth of first child years } \\
\hline No children & $12.6(48 / 382)$ & $0.96(0.63-1.47)$ & 0.86 \\
\hline $13-20$ years & $14.5(95 / 655)$ & $1.25(0.89-1.76)$ & 0.20 \\
\hline $21-24$ years & $11.1(72 / 649)$ & 1.0 & \\
\hline $25-28$ years & $13.8(83 / 601)$ & $1.19(0.84-1.69)$ & 0.33 \\
\hline $29-45$ years & $11.8(55 / 468)$ & $1.05(0.71-1.54)$ & 0.81 \\
\hline
\end{tabular}




\begin{tabular}{|c|c|c|c|}
\hline \multirow[t]{2}{*}{ Variable } & \multicolumn{2}{|c|}{ Middle-aged current asthma } & \multirow[t]{2}{*}{ p-value } \\
\hline & $\%(n / N)$ & OR $(95 \% \mathrm{CI})$ & \\
\hline \multicolumn{4}{|l|}{ HC use } \\
\hline Never & $9.2(10 / 109)$ & 1.0 & \\
\hline Past & $12.3(256 / 2089)$ & $1.36(0.68-2.74)$ & 0.39 \\
\hline Current & $15.1(83 / 551)$ & $1.58(0.76-3.29)$ & 0.22 \\
\hline \multicolumn{4}{|l|}{ Duration of $\mathrm{HC}$ use } \\
\hline Nil & $9.2(10 / 109)$ & 1.0 & \\
\hline $0.1-5$ years & $16.6(97 / 583)$ & $1.98(0.96-4.09)$ & 0.06 \\
\hline $5.1-10$ years & $10.0(66 / 660)$ & $1.11(0.53-2.31)$ & 0.78 \\
\hline $10.1-15$ years & $12.1(62 / 513)$ & $1.35(0.64-2.83)$ & 0.43 \\
\hline $15.1-20$ years & $13.4(61 / 455)$ & $1.45(0.69-3.05)$ & 0.33 \\
\hline $20.1-25$ years & $12.5(40 / 320)$ & $1.24(0.57-2.71)$ & 0.58 \\
\hline $25.1-30$ years & $12.7(14 / 110)$ & $1.19(0.47-3.03)$ & 0.71 \\
\hline Per year of use of $\mathrm{HCs}$ & & $0.99(0.97-1.01)$ & 0.23 \\
\hline \multicolumn{4}{|l|}{ Age at start of $\mathrm{HC}$ use } \\
\hline Never & $9.2(10 / 109)$ & 1.0 & \\
\hline $12-16$ years & $14.73(105 / 713)$ & 1.58 (0.77-3.25) & 0.22 \\
\hline $17-18$ years & $12.20(131 / 1074)$ & $1.37(0.67-2.79)$ & 0.39 \\
\hline 19-42 years & $12.13(102 / 841)$ & $1.35(0.65-2.78)$ & 0.42 \\
\hline
\end{tabular}

asthma after menarche associated with an early age at menarche. Prolonged hormonal contraceptive use was also a risk factor for middle-aged current asthma in women who were overweight or obese. Furthermore, our study showed that asthma risk was significantly associated with $\mathrm{HC}$ use for $\geqslant 11$ years. While our results on the interaction between $\mathrm{HC}$ use and obesity confirm previous findings from one other population-based study [8], we are the first to investigate and demonstrate the role of duration of $\mathrm{HC}$ use in this association.

Our finding of an association between early age at menarche and middle-aged current asthma and any asthma after menarche is consistent with reports from previous studies. SALAM et al. [2] found that women who had menarche before the age of 12 years had a 2.08-fold higher risk of asthma after puberty. MACSALI et al. [11] examined European Community Respiratory Health Survey data and found forced expiratory volume in $1 \mathrm{~s}$ and forced vital capacity were lower and asthma was more common in women with early menarche ( $\leqslant 10$ years). We did not observe any modification of the association between early age at menarche and asthma risk by BMI in childhood or adulthood. One study had demonstrated an association between current adult BMI and asthma severity, which was stronger in the subgroup of women with early menarche ( $\geqslant 11$ years) [21].

The current evidence on biological mechanisms supports the interaction between HC use, specifically oral contraceptive pill (OCP) use, and obesity in increasing the risk of asthma. The OCP provides moderate,

FIGURE 1 The association between years of hormonal contraceptive use and probability of current asthma in middle age, stratified by body mass index. Circles represent the probability of current asthma and the bars represent the $95 \%$ confidence interval of that probability.

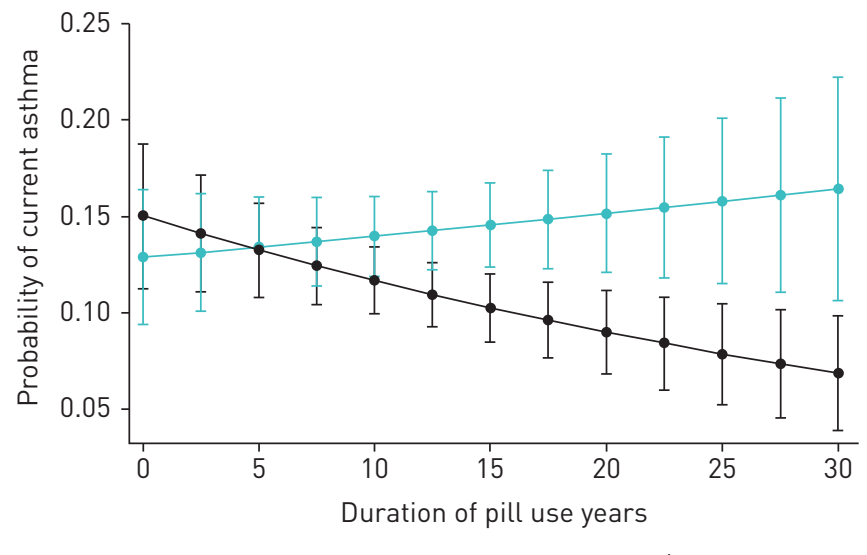

$\multimap$ Normal $\multimap$ Overweight/obese 


\begin{tabular}{|c|c|c|}
\hline Duration of $\mathrm{HC}$ use & $\mathrm{OR}^{\#}(95 \% \mathrm{CI})$ & $\mathrm{p}$-value \\
\hline Nil & $0.83(0.54-1.29)$ & 0.413 \\
\hline 5 years & $1.01(0.74-1.39)$ & 0.932 \\
\hline 10 years & $1.23(0.97-1.57)$ & 0.093 \\
\hline 15 years & 1.50 (1.15-1.95) & 0.003 \\
\hline 20 years & $1.82(1.27-2.61)$ & 0.001 \\
\hline 25 years & $2.21(1.35-3.61)$ & 0.001 \\
\hline 30 years & $2.69(1.43-5.05)$ & 0.002 \\
\hline
\end{tabular}

consistent levels of both oestrogen and progesterone, in the case of a combined OCP, or progesterone, in the case of a progesterone-only OCP. These hormones suppress the release of luteinising hormone and follicle-stimulating hormone that trigger the surge of progesterone immediately after ovulation [22]. These persistently elevated levels of oestrogen and/or progesterone beyond the body's normal rhythm may increase generalised systemic inflammation. Evidence from animal studies has shown that $\beta$-oestradiol, administered at doses comparable to those used for contraceptive purposes, decreased T-helper (Th) 1 responses including suppressing interleukin (IL)-2 and interferon (IFN)- $\alpha$ production, while increasing Th2 responses by increasing gene expression of the Th2 cytokines IL-4 and IL-10 [23]. Furthermore, progesterone administered exogenously to ovalbumin-sensitised BALB/c mice led to enhanced bronchial hyperresponsiveness, elevated airway eosinophilia and elevated systemic IL-5 levels [24]. In studies of human peripheral blood mononuclear cells, the administration of oestrogen or progesterone to levels equivalent to those seen in pregnancy induced production of the Th2 cytokines IL-4 and IL-13 [25]. In humans, the strongest evidence of female sex hormones influencing the Th1/Th2 balance comes from the co-existence of persistently elevated progesterone levels and Th2 skewness during pregnancy. Furthermore, progesterone appears to influence IL-4 production by T-cells during pregnancy [26]. To date, no published study has examined the effects of non-pregnancy-like concentrations of oestrogen or progesterone on systemic or airway inflammation.

Similarly, it is hypothesised that the well-established relationship between BMI and asthma may at least be partly related to systemic inflammatory effects, with an alternative explanation being the mechanical effect of obesity. Obesity is associated with a state of chronic, low grade inflammation [27]. In obese individuals, there is an increase in the number of macrophages in adipose tissue, which can then secrete a number of inflammatory molecules including leptin, tumour necrosis factor $\alpha$, IL-6, tumour growth factor-b1 and eotaxin [28]. This proinflammatory state has been suggested as contributing to a wide range of metabolic disturbances that include insulin resistance, dyslipidaemia and the metabolic syndrome [29]. However, how this systemic inflammation may lead to airway inflammation and asthma is not well understood. Evidence from animal models has shown that obese mice sensitised to ovalbumin have altered T-cell responses, IFN- $\gamma$ production and mast cell numbers when compared to lean control animals [30]. Furthermore, obese mice have been shown to have increased airway responsiveness to exogenous stimuli [31] and administration of leptin has been shown to increase airway responsiveness in sensitised mice [32]. So, while the continuous elevation of oestrogen and progesterone at a moderate level leading to continuous systemic inflammation and Th1/Th2 imbalance individually may not be sufficient for asthma, when combined with obesity, the compounding effects may surpass a threshold level of airway inflammation critical for development of symptoms.

Our findings for HC are similar to those from a study by MACSALI et al. [8], who found that OCP use was associated with an increased risk of asthma, asthma with hay fever, wheeze with shortness of breath, hay fever and more than three asthma symptoms. These associations were present only in normal and overweight women, not lean women. Another study of younger women by SALAM et al. [2] found that in nonasthmatics, OCP use was associated with a higher risk of current wheeze but, conversely, in asthmatics, such use reduced the prevalence of current wheeze. We have previously shown, with an earlier follow-up of the TAHS, an increased risk of new-onset asthma developed after the age of 7 years was associated with increased parity and decreased oral contraceptive pill use [33]. This is consistent with our current findings for normal-weight women, where increasing years of pill use reduced the risk of asthma at the age of 43 years. However, we did not observe any interaction between increasing parity and HC use. The small difference in the findings may be due to the fact that the studies were conducted at different points in the women's reproductive lives, i.e. the present analysis was conducted when the women were entering the perimenopausal period. Another reason for the small difference in the findings between the current and 
previous analyses may be related to the risk of metabolic syndrome, which increases with ageing, which can then modify the effect of exogenous hormones.

This study has some limitations, which include retrospective recall of HC use and other reproductive factors. Most of the reproductive factors examined in this analysis are major life events and most women are likely to recall them accurately [34]. The retrospective recall of $\mathrm{HC}$ use may be less reliable and subject to some recall error. Our definition of $\mathrm{HC}$ use was not specific for the combined OCP, and women who were using other hormonal contraceptives including implants or injections would have provided an affirmative response. However, a recent Australian study of young women reported that $95.5 \%$ of women using HCs were using the OCP [35], and it is likely that a similar proportion would have been using the combined OCP in our study. We do not have objective measures of hormone levels in our study and this limits our ability to explore the biological mechanisms for the observed associations. The use of participants' reporting of asthma is a limitation as it is likely to be less reliable than physician reporting or objective measures of lung function and bronchial hyperresponsiveness. However, the question used in TAHS to define asthma has been validated against physician diagnosis [36], and has been shown to be valid and reliable. Adult BMI may be subjected to random error, as it was calculated from self-reported height and weight. However, other studies have found self-reported height and weight to be fairly reliable [37].

In conclusion, we provide further evidence for the postulated association between very early menarche and asthma. We have also found that longer term HC use was associated with an increased risk of asthma among overweight or obese women. These findings add to the existing literature that suggests exogenous sex hormones may interact with metabolic status to affect respiratory health. This has important implications for physicians prescribing $\mathrm{HC}$ for women who are overweight or obese and may indicate that long-term use of HCs in this subgroup of women is not advisable. Further long-term studies in perimenopause and menopause on the interaction between HCs and obesity are needed.

\section{Acknowledgements}

We acknowledge the continued support and participation of the Tasmanian Longitudinal Health Study (TAHS) participants and acknowledge all previous investigators of the TAHS.

\section{References}

1 Becklake MR, Kauffmann F. Gender differences in airway behaviour over the human life span. Thorax 1999; 54: 1119-1138.

2 Salam MT, Wenten M, Gilliland FD. Endogenous and exogenous sex steroid hormones and asthma and wheeze in young women. J Allergy Clin Immunol 2006; 117: 1001-1007.

3 Larsson L. Incidence of asthma in Swedish teenagers: relation to sex and smoking habits. Thorax 1995; 50: 260-264.

4 Sinclair AH, Tolsma DD. Gender differences in asthma experience and disease care in a managed care organization. J Asthma 2006; 43: 363-367.

5 Balzano G, Fuschillo S, Melillo G, et al. Asthma and sex hormones. Allergy 2001; 56: 13-20.

6 van den Berge M, Heijink HI, van Oosterhout AJ, et al. The role of female sex hormones in the development and severity of allergic and non-allergic asthma. Clin Exp Allergy 2009; 39: 1477-1481.

7 Real FG, Svanes C, Björnsson EH, et al. Hormone replacement therapy, body mass index and asthma in perimenopausal women: a cross sectional survey. Thorax 2006; 61: 34-40.

8 Macsali F, Real FG, Omenaas ER, et al. Oral contraception, body mass index, and asthma: a cross-sectional Nordic-Baltic population survey. J Allergy Clin Immunol 2009; 123: 391-397.

9 Herrera-Trujillo M, Barraza-Villarreal A, Lazcano-Ponce E, et al. Current wheezing, puberty, and obesity among mexican adolescent females and young women. J Asthma 2005; 42: 705-709.

10 Troisi RJ, Speizer FE, Willett WC, et al. Menopause, postmenopausal estrogen preparations, and the risk of adult-onset asthma - a prospective cohort study. Am J Respir Crit Care Med 1995; 152: 1183-1188.

11 Macsali F, Real FG, Plana E, et al. Early age at menarche, lung function, and adult asthma. Am J Respir Crit Care Med 2011; 183: 8-14.

12 Barr RG, Wentowski CC, Grodstein F, et al. Prospective study of postmenopausal hormone use and newly diagnosed asthma and chronic obstructive pulmonary disease. Arch Intern Med 2004; 164: 379-386.

13 Moore WC, Meyers DA, Wenzel SE, et al. Identification of asthma phenotypes using cluster analysis in the Severe Asthma Research Program. Am J Respir Crit Care Med 2010; 181: 315-323.

14 Chen W, Mempel M, Schober W, et al. Gender difference, sex hormones, and immediate type hypersensitivity reactions. Allergy 2008; 63: 1418-1427.

15 Von Behren J, Lipsett MH-RP, Delfino RJ, et al. Obesity, waist size and prevalence of current asthma in the California Teachers Study cohort. Thorax 2009; 64: 889-893.

16 Giles GG, Lickiss N, Gibson HB. Respiratory symptoms in Tasmanian adolescents: a follow up of the 1961 birth cohort. Aust NZ J Med 1984; 14: 631-637.

17 Jenkins MA, Hopper JL, Bowes G, et al. Factors in childhood as predictors of asthma in adult life. BMJ 1994; 309: 90-93.

18 Wharton CL, Dharmage SC, Jenkins MA, et al. Tracing 8,600 participants 36 years after recruitment at age 7 for the Tasmanian Asthma Study. Aust NZ J Public Health 2006; 30: 105-110.

19 Obesity: preventing and managing the global epidemic. Report of a WHO consultation. World Health Organ Tech Rep Ser 2000; 894: 1-253. 
24 Hellings

hyper-responsiveness in a murine model of allergic asthma. Clin Exp Allergy 2003; 33: 1457-1463.

25 Hamano N, Terada N, Maesako K, et al. Effect of female hormones on the production of IL-4 and IL-13 from peripheral blood mononuclear cells. Acta Otolaryngol Suppl 1998; 537: 27-31.

26 Melgert BN, Ray A, Hylkema MN, et al. Are there reasons why adult asthma is more common in females? Curr Allergy Asthma Rep 2007; 7: 143-150.

27 Dixon AE, Holguin F, Sood A, et al. An official American Thoracic Society Workshop report: obesity and asthma. Proc Am Thorac Soc 2010; 7: 325-335.

28 Ferrante AW. Obesity-induced inflammation: a metabolic dialogue in the language of inflammation. J Intern Med 2007; 262: 408-414.

29 Haffner S, Taegtmeyer H. Epidemic obesity and the metabolic syndrome. Circulation 2003; 108: 1541-1545.

30 Mito N, Kitada C, Hosoda T, et al. Effect of diet-induced obesity on ovalbumin-specific immune responses in a murine asthma model. Metabolism 2002; 51: 1241-1246.

31 Shore SA, Rivera-Sanchez YM, Schwartzman IN, et al. Responses to ozone are increased in obese mice. J Appl Physiol 2003; 95: 938-954.

32 Shore SA, Schwartzmann IN, Mellema MS, et al. Effect of leptin on allergic airway responses in mice. J Allergy Clin Immunol 2005; 115: 103-109.

33 Jenkins MA, Dharmage SC, Flander LB, et al. Parity and decreased use of oral contraceptives as predictors of asthma in young women. Clin Exp Allergy 2006; 36: 609-613.

34 Must A, Phillips SM, Naumova EN, et al. Recall of early menstrual history and menarcheal body size: after 30 years, how well do women remember? Am J Epidemiol 2002; 155: 672-679.

35 Greig AJ, Palmer MA, Chepulis LM. Hormonal contraceptive practices in young Australian women ( $\leqslant 25$ years) and their possible impact on menstrual frequency and iron requirements. Sex Reprod Healthc 2010; 1: 99-103.

36 Jenkins MA, Clarke JR, Carlin JB, et al. Validation of questionnaire and Bronchial Hyperresponsiveness against Respiratory Physician Assessment in the Diagnosis of Asthma. Int J Epidemiol 1996; 25: 609-616.

37 Field AE, Aneja P, Rosner B. The validity of self-reported weight change among adolescents and young adults. Obesity (Silver Spring) 2007; 15: 2357-2364. 